\title{
RADIOCARBON AGE ANOMALIES IN LAND SNAIL SHELLS FROM TEXAS: ONTOGENETIC, INDIVIDUAL, AND GEOGRAPHIC PATTERNS OF VARIATION
}

\author{
Glenn A Goodfriend ${ }^{1} \bullet$ G Lain Ellis ${ }^{2} \bullet$ L J Toolin ${ }^{3}$
}

\begin{abstract}
Accelerator mass spectrometric (AMS) radiocarbon analyses of live-collected, prebomb samples of shell carbonates of the land snails Rabdotus dealbatus and $R$. alternatus from Texas were carried out to quantify the characteristic age anomalies of land snails from limestone areas. Age anomalies are similar for the two species; they average $+700 \mathrm{yr}$ and vary by $\pm 180 \mathrm{yr}(1 \sigma)$ among samples. Serial analysis of 1 shell reveals a significant ontogenetic trend in ${ }^{14} \mathrm{C}$ age anomalies, with older apparent ages (up to $1200 \mathrm{yr}$ ) in the apical part of the shell and younger and uniform ages in the last whorl. No trend in age anomalies was found across a broad range of rainfall conditions (from 300 to $1000 \mathrm{~mm}$ mean annual rainfall).
\end{abstract}

\section{INTRODUCTION}

A number of earlier studies have established that land snail shell carbonate typically has a radiocarbon age anomaly: the measured ${ }^{14} \mathrm{C}$ age is older than the actual age, as a result of ingestion of old carbonate (e.g., limestone) and its incorporation into the shell (Evin et al. 1980; Burleigh and Kerney 1982; Goodfriend and Stipp 1983; Goodfriend and Hood 1983; Goodfriend 1987). The ingested carbonate dissolves in the stomach acid, producing $\mathrm{CO}_{2}$, which dissolves in the body fluids to become part of the bicarbonate pool. This bicarbonate pool is the source material from which calcium carbonate is precipitated during the process of shell growth (Goodfriend and Hood 1983).

In recent years, accelerator mass spectrometric (AMS) analysis of samples for ${ }^{14} \mathrm{C}$ has become common. Because the amount of sample required for analysis of carbonates ( $12 \% \mathrm{C}$ by weight) by AMS is only about $10-20 \mathrm{mg}$, it is now possible to analyze even rather small individual shells or parts of larger shells. Conventional analysis ( $\beta$-decay counting) requires about 1000 times this amount, so that much of the previous work on fossil land snails involved analysis of bulk samples (i.e., comprised of many individuals) or whole shells of very large land snails. Previous studies on modern land snail shells, aimed at quantifying ${ }^{14} \mathrm{C}$ age anomalies, were also based primarily upon analysis of bulk samples or very large individual shells. Such analyses have been used to compare variation in age anomalies among species or between different regions (e.g., Goodfriend and Stipp 1983). But how much variation in age anomalies occurs among individuals of the same population or within an individual shell as it grows? For AMS analyses, it is important to establish to what degree such variation may contribute to the overall variability of age anomalies in order to quantify uncertainties of corrected ${ }^{14} \mathrm{C}$ ages and also to develop a sampling strategy to minimize such variability.

Shells of the land snail Rabdotus are abundant in archeological sites as well as in alluvial and cave deposits throughout much of the southern Great Plains. They have been widely used for ${ }^{14} \mathrm{C}$ dating (Stafford 1993; Ellis and Goodfriend 1994; Ellis et al. 1996; Abbott et al. 1995; Abbott et al. 1996; Toomey and Stafford 1994; Quigg et al. 1996; Johnson forthcoming). Thus, it is important to establish the age anomalies in these snails on a quantitative basis so that accurate results may be obtained from ${ }^{14} \mathrm{C}$ dates on fossil samples.

In the present study, we looked at ${ }^{14} \mathrm{C}$ age anomalies in 2 species of sympatric land snails of the genus Rabdotus (dealbatus and alternatus) in Texas, based on analysis of modern, prebomb shells (i.e., shells collected alive before the thermonuclear bomb tests of the late 1950s significantly raised atmospheric ${ }^{14} \mathrm{C}$ levels) obtained from museum collections. For 1 shell, we examined ontogenetic

\footnotetext{
${ }^{1}$ Department of Geology, George Washington University, Washington, DC 20052 USA

${ }^{2}$ Environmental Affairs Division, Texas Department of Transportation, 125 E 11 th St, Austin, TX 78701-2483 USA

${ }^{3}$ NSF AMS Facility, University of Arizona, PO Box 210081, Tucson, AZ 85721 USA
} 
variation within the shell by analyzing a series of samples taken from the upper whorls (the earliest part of shell growth) to the lip (the last part of the shell to be deposited). We examined variation among individual shells from the same collection and differences in age anomalies between the 2 species. We also evaluated possible geographic trends in age anomalies in relation to environmental gradients. Our samples of Rabdotus come from environments ranging from moist eastern Texas, receiving about $1000 \mathrm{~mm}$ mean annual rainfall and supporting deciduous forest, to dry western Texas, receiving only $300 \mathrm{~mm}$ rainfall and supporting a sparse desert scrub vegetation (Figure 1).

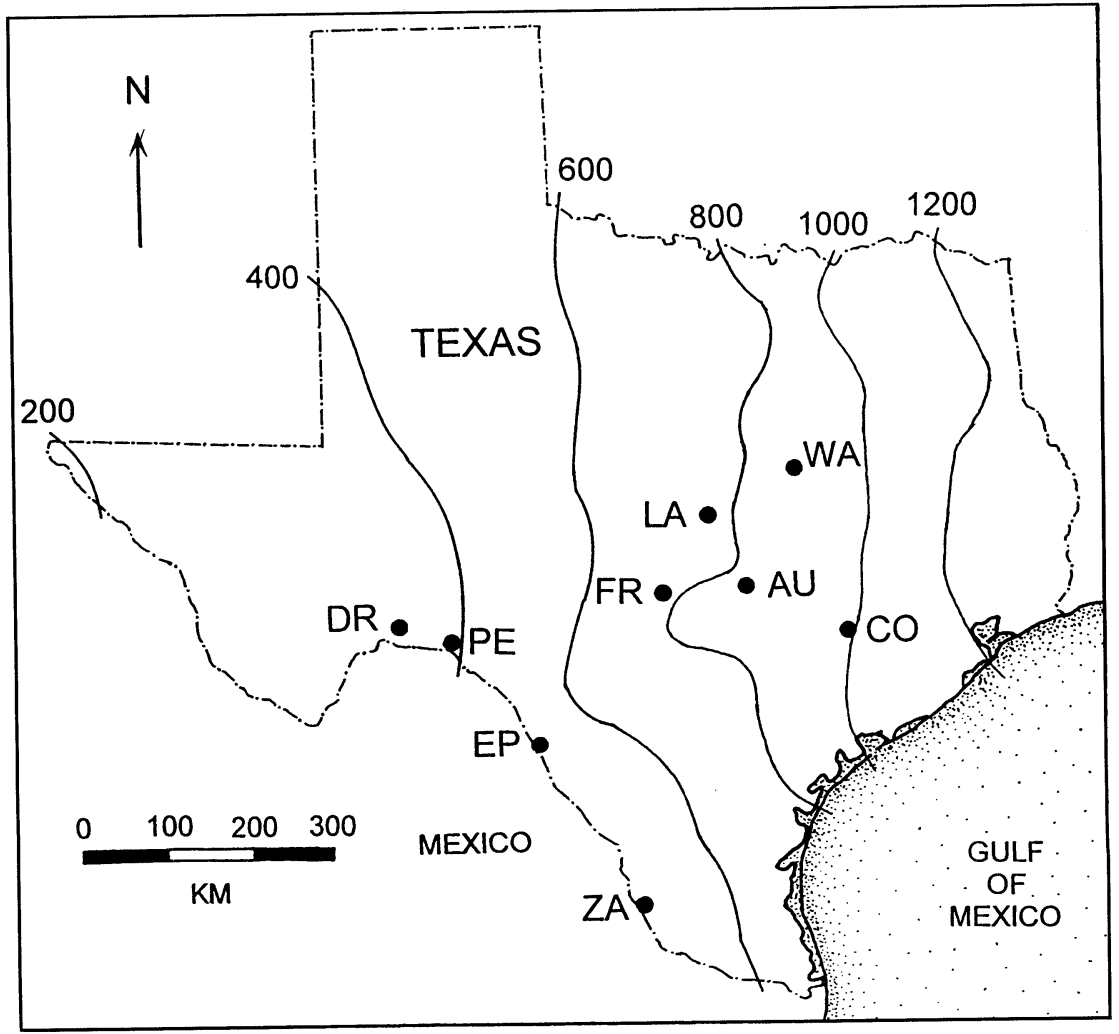

Figure1 Map of Texas, showing locations of samples analyzed and mean annual rainfall isohyets (in $\mathrm{mm}$ ) (see Table 2 for site abbreviations)

\section{MATERIALS AND METHODS}

Live-collected, prebomb Rabdotus shell samples were obtained from the collection of the US National Museum of Natural History. Individuals from 10 samples of snails were analyzed, including 7 samples of $R$. dealbatus ${ }^{4}$ and 3 samples of $R$. alternatus. The samples come from 9 localities, with both species obtained from one of the sites. Prebomb shells are used for these analyses in order to maximize the precision of the age anomaly estimates. Since postbomb atmospheric ${ }^{14} \mathrm{C}$ levels

${ }^{4}$ We have included $R$. mooreanus under $R$. dealbatus. $R$. mooreanus was considered a subspecies of $R$. dealbatus by Pilsbry (1946). It was tentatively elevated to specific status by Fullington and Pratt (1974) but without supporting anatomical analysis. We consider that determination of the correct status of this form awaits detailed anatomical and genetic study and that available information on shell morphology does not warrant specific recognition of this form. 
vary significantly from year to year and also geographically, it is difficult accurately to estimate reference atmospheric ${ }^{14} \mathrm{C}$ levels for postbomb snails that live for longer than 1 year, as Rabdotus does.

Individual shells were usually sampled by cutting a strip of shell from roughly the last third of the shell (perpendicular to the lip and the growth lines), using a Dremel tool with a 1-inch circular saw blade. The strips were cleaned by sonication in distilled water, then dried. Such a sample is representative of the later phase of growth of the shell. In order to obtain representative values for each of a series of localities across the rainfall gradient, samples were pooled from 3 to 6 individuals. For 1 sample, each of 5 shells was analyzed individually to examine among-individual variation. One shell was also selected for analysis of 5 serial samples. These samples were removed as powders, using a motorized Dremel tool fitted with a dental bit.

Corrections for isotopic fractionation were made based on measurement of the $\delta^{13} \mathrm{C}$ values. The ${ }^{14} \mathrm{C}$ activity of the atmosphere contemporary with the snails (i.e., at the time of collection of each sample) was determined from analyses of tree rings by Stuiver and Becker (1993). To calculate the age anomaly, these apparent ages of atmospheric carbon were subtracted from the shell ${ }^{14} \mathrm{C}$ ages.

Mean annual rainfall amounts for 1931-1960 were interpolated for the sites from which snail samples were analyzed based on data of the US Environmental Data Service (1969).

\section{RESULTS}

\section{Ontogenetic Variation}

Five samples were analyzed from a specimen of Rabdotus alternatus from Eagle Pass, from the lip up to $66 \mathrm{~mm}$ toward the apex of the shell (as measured along the periphery of the shell). The 3 samples from the last whorl of the shell ( 0 to $13 \mathrm{~mm}$ from the lip) all show apparent ${ }^{14} \mathrm{C}$ ages averaging $770 \mathrm{yr}$, with a standard deviation $(\sigma)$ of $30 \mathrm{yr}$ (Figure 2). The $\sigma$ is actually less than the average analytical error $(60 \mathrm{yr})$ and indicates no measurable difference between the apparent ages of these 3 samples. On the other hand, the sample at $40.5 \mathrm{~mm}$ from the lip shows a significantly higher ${ }^{14} \mathrm{C}$ age of $955 \pm 50 \mathrm{yr}$ and the most apical sample at $66 \mathrm{~mm}$ shows a still higher apparent age of $1200 \pm 50$ yr. Thus there is a trend of decreasing ${ }^{14} \mathrm{C}$ ages from the apex to the last whorl of the shell, with the last whorl showing uniform values.

The upper (more apical) part of the shell is laid down during the juvenile stage of the snail, whereas the last whorl is laid down as the snail is approaching adulthood. It may be that the faster growth rate associated with juveniles requires the snails to ingest more calcium (in the form of limestone) for

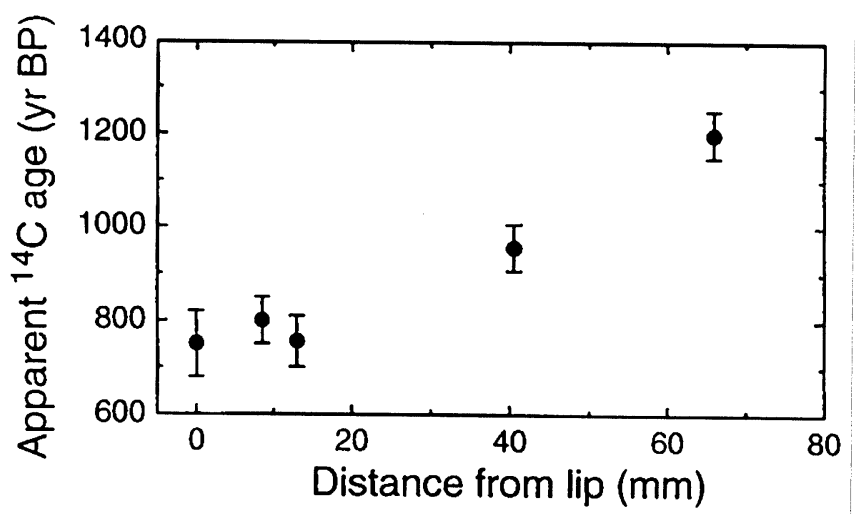

Figure 2 Variation in apparent ${ }^{14} \mathrm{C}$ age of shell carbonate in a specimen of Rabdotus alternatus from Eagle Pass. The positions of the samples are given in relation to their distance from the lip, as measured along the periphery of the shell, so that the lip sample is plotted at 0 $\mathrm{mm}$ and the samples nearer to the apex of the shell are to the right of the figure. Error bars are the $\pm 1 \sigma$ uncertainties of the ${ }^{14} \mathrm{C}$ ages. 
their shells, whereas in the more mature snails, the diet of plant material may suffice to provide the smaller amount of calcium needed for slower shell growth. For Rabdotus, it seems that taking samples for ${ }^{14} \mathrm{C}$ analysis only from the last whorl of the shell will minimize age anomalies. Furthermore, a consistent sampling position should lead to more uniform results.

\section{Variation among Individuals from the Same Population}

Besides the specimen on which serial analyses were carried out, 4 additional shells of $R$. alternatus from Eagle Pass were analyzed for apparent ${ }^{14} \mathrm{C}$ ages to examine variation among individuals collected from the same place at the same time. The mean apparent age of these 5 samples (Table 1) is $855 \mathrm{yr}, \sigma=155 \mathrm{yr}$. Part of this $\sigma$ is the result of analytical error, rather than intrinsic variability of age anomalies. To obtain this intrinsic component of variability, the variance $\left(s^{2}\right)$ of the average analytical error $(\sigma=70 \mathrm{yr})$ was subtracted from the overall variance $\left(155^{2}\right)$. This leaves a net $\sigma$ of 135 yr. This indicates that variation in age anomalies among individuals is on the order of $100 \mathrm{yr}$. However, 4 of the 5 shells (A-D) show relatively uniform ages (mean of $790 \mathrm{yr}, \sigma=85 \mathrm{yr}$ ). The variability among these 4 shells is little more than their average analytical error $(65 \mathrm{yr})$. So most of the variability observed among the shells is the result of a single individual (E) with an unusually high age anomaly.

Table 1 Variation in ${ }^{14} \mathrm{C}$ age anomalies among individual shells of Rabdotus alternatus from Eagle Pass

\begin{tabular}{llcc}
\hline Specimen & Lab nr & $\delta^{13} \mathrm{C}$ & $\begin{array}{c}\text { Apparent }{ }^{14} \mathrm{C} \text { age } \\
(\text { yr BP })\end{array}$ \\
\hline $\mathrm{A}^{\mathrm{a}}$ & - & -10.1 & $770 \pm 55$ \\
$\mathrm{~B}$ & $\mathrm{AA}-20602$ & - & $810 \pm 95$ \\
$\mathrm{C}$ & $\mathrm{AA}-20603$ & -9.8 & $695 \pm 65$ \\
$\mathrm{D}$ & $\mathrm{AA}-20604$ & -5.7 & $895 \pm 50$ \\
$\mathrm{E}$ & $\mathrm{AA}-20605$ & -9.8 & $1095 \pm 85$ \\
& & Mean & $\mathbf{8 5 5}$ \\
& & $\sigma$ & 155 \\
& & Net $\sigma^{\mathrm{b}}$ & $\mathbf{1 3 5}$ \\
\hline
\end{tabular}

a Mean value for 3 samples from the last $1 / 3$ whorl of the shell (Figure 2)

${ }^{b} \mathrm{Net} \sigma$ is the $\sigma$ after removal of the average analytical error $(70 \mathrm{yr})$

Although not large, the among-individual variability does contribute some uncertainty to the age anomaly correction factor. For this reason, bulk analyses of many individuals actually have an advantage over AMS analyses of individual shells as they tend to mask the among-individual variation. Characterization of age anomalies for comparison of species and evaluation of geographic trends was therefore based on analysis of pooled samples of 3 to 6 individual shells.

\section{Differences in Age Anomalies between Species}

Table 2 gives the results of analyses of $7 R$. dealbatus samples and $3 R$. alternatus samples; the 2 species were collected together at 1 locality (Eagle Pass). In comparing these samples, it is necessary to compare the age anomalies (the deviation of apparent ${ }^{14} \mathrm{C}$ ages from contemporary atmospheric ${ }^{14} \mathrm{C}$ ages) rather than the apparent ages themselves, since the samples were collected at different times when the atmospheric ${ }^{14} \mathrm{C}$ levels were different (Table 2). No difference in the mean age anomaly is seen between the 2 species (mean \pm standard error: $+680 \pm 65$ for $R$. dealbatus; $+715 \pm$ 160 for $R$. alternatus). Samples of the 2 species from Eagle Pass do differ in apparent age by $235 \mathrm{yr}$, 


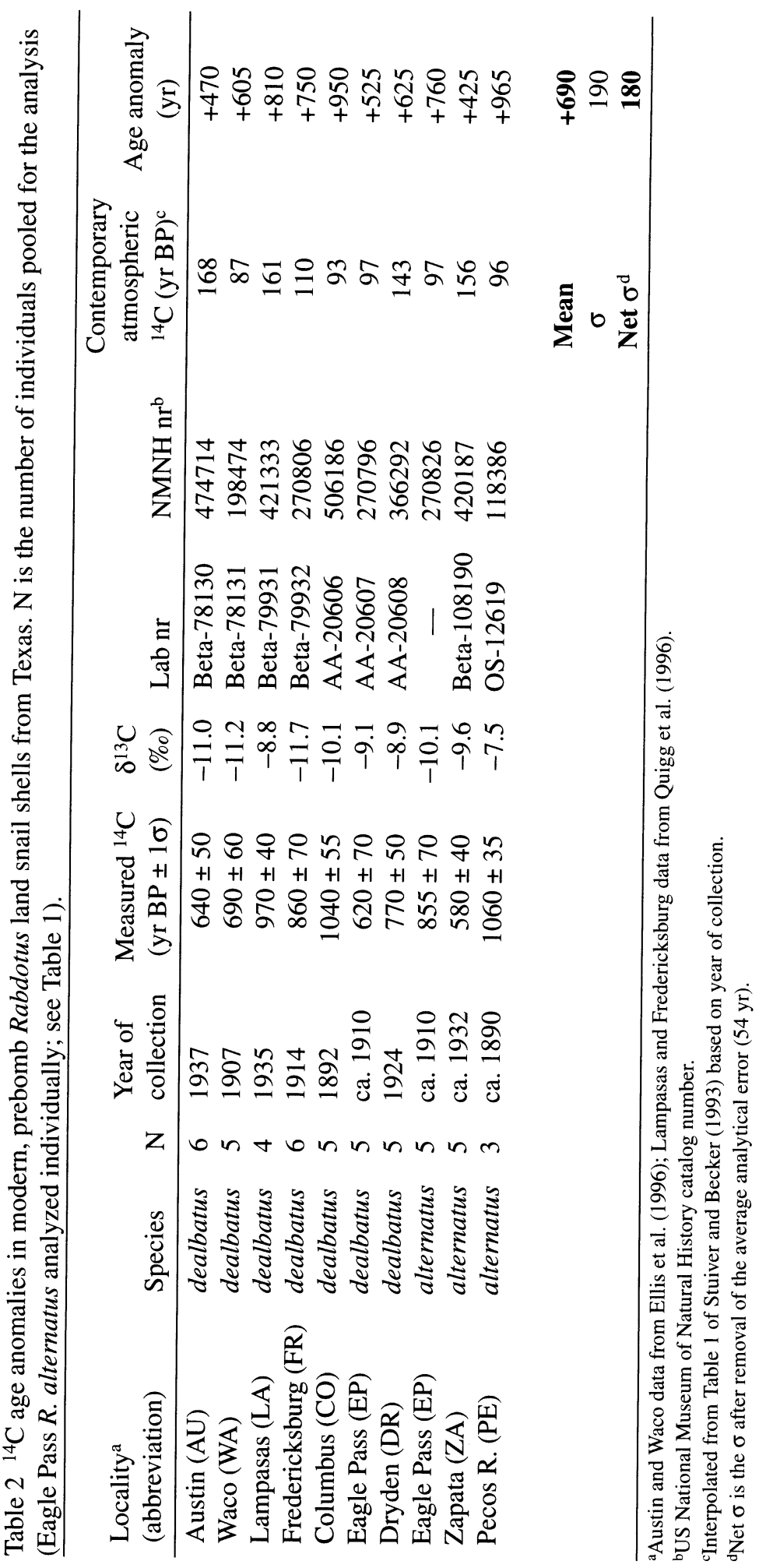


but this difference is similar to the average $\sigma(190 \mathrm{yr})$ seen in the overall data set. The available data thus show no difference in age anomalies between these 2 species of Rabdotus.

\section{Possible Geographic Trends in Age Anomalies in Relation to Rainfall}

When the ${ }^{14} \mathrm{C}$ age anomalies of the Rabdotus samples are plotted in relation to the mean annual rainfall of the sites from which they were collected, no trend of ages is apparent $(r=0.15)$ (Figure 3). Rainfall is the predominant environmental variable through the region and is related to vegetation type (including forest, prairie, woodland, and desert scrub within the region) and density, as well as to soils. Rainfall also directly affects the activity and growth rates of snails, which in turn may affect calcium requirements. Despite this wide range of environmental conditions represented by the samples, the age anomalies are not obviously influenced by them.

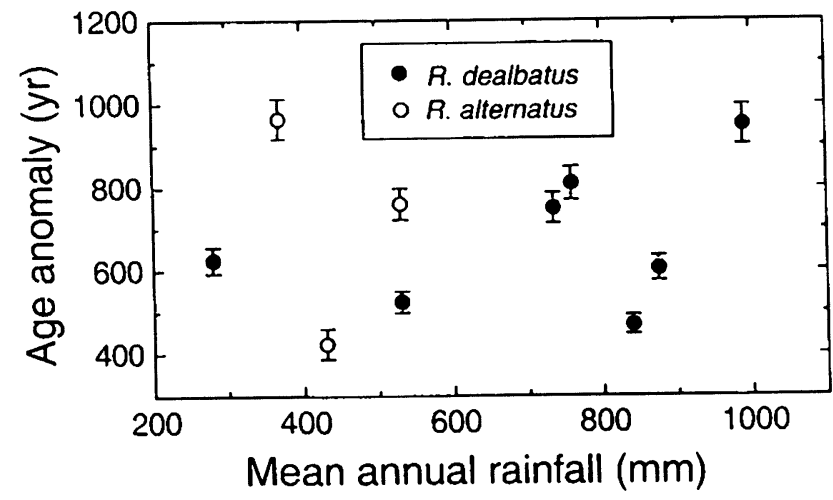

Figure $3{ }^{14} \mathrm{C}$ age anomalies of Rabdotus dealbatus and $R$. alternatus shells in relation to mean annual rainfall (ages from Table 2). See Figure 1 for locations of samples.

The substrate of central and southern Texas consists mostly of limestone or sediments derived from limestone regions. Since the samples come from a museum collection and generally have only the name of the town indicated, rather than more precise locality information, it is not possible to tell in which cases samples may have been collected on alluvial sediments where snails would not have access to limestone bedrock. The Columbus site on the coastal plain is on Quaternary alluvium, the upland source of which lies on limestone. The Zapata site lies on sandstone terrain but shells could be from an alluvial context. The area around Lampasas has both sandstone and limestone bedrock.

At localities where limestone bedrock is not accessible to snails, carbonate-containing sediments (such as alluvium or eolian sediments) may be utilized. If the carbonate in these sediments is of relatively recent origin (derived from soil carbonates or freshwater precipitates, rather than from limestone clasts), then consumption of these by snails would produce a reduced ${ }^{14} \mathrm{C}$ age anomaly, depending on the apparent age of the carbonates.

\section{Correcting Fossil Rabdotus ${ }^{14} \mathrm{C}$ Ages for Age Anomalies}

The analyses presented above indicate that modern prebomb Rabdotus dealbatus and $R$. alternatus shells have an average age anomaly of $+700 \mathrm{yr}$. In order to correct ${ }^{14} \mathrm{C}$ ages of fossil Rabdotus for age anomalies, this amount should be subtracted from the apparent ages, before calibration. Because the age anomalies do not appear to depend on climatic conditions such as rainfall (based on modern geographic variation), this correction should be applicable to fossil samples, even if the past climates they lived under were different from the modern climate.

The age anomalies are variable, however, and this must be taken into account in calculating the overall error of the corrected ${ }^{14} \mathrm{C}$ ages. Among-sample variation (based on bulk samples of about 5 
shells) is estimated at $180 \mathrm{yr}(\sigma)$. This would be the appropriate number to combine with the analytical error of a fossil sample (the variances sum) to obtain the error of the corrected age, if the fossil sample is also a bulk sample of about this number of individuals. However, if the fossil sample consists of only 1 shell, then there will be a slightly larger variability of the age anomaly, because among-individual variation exceeds analytical error (net $\sigma$ of $135 \mathrm{yr}$ ). To calculate what the overall error should be for a single shell, we must first calculate the expected among-sample component of the variability by subtracting the average standard error of each sample (assumed to be represented by the multiple analyses of $R$. alternatus individuals from Eagle Pass, or $135 / \sqrt{ } 5=60 \mathrm{yr}$ ) from the net $\sigma$ of $180 \mathrm{yr}\left(\sqrt{ }\left(180^{2}-60^{2}\right)=170 \mathrm{yr}\right)$. To this value of $170 \mathrm{yr}$ for the among-sample component of variation, we must add the among individual variation $(\sigma=135 \mathrm{yr})$ to obtain the overall error of the age anomaly correction for an individual shell analysis: $\sqrt{ }\left(170^{2}+135^{2}\right)=210 \mathrm{yr}$. This error is slightly larger (by $30 \mathrm{yr}$ ) than the error for bulk samples (for $n=5$ ). To obtain the overall error of the corrected ${ }^{14} \mathrm{C}$ age $\left(\sigma_{\text {total }}\right)$ for a fossil sample, the error of the age anomaly must be combined with the analytical error for the fossil sample as reported by the ${ }^{14} \mathrm{C} \mathrm{lab}\left(\sigma_{\mathrm{lab}}\right)$. Thus the overall errors may be calculated according to the following formulae:

$$
\begin{aligned}
& \text { for individual shell: } \sigma_{\text {total }}=\sqrt{210^{2}+\sigma_{\text {lab }}^{2}} \\
& \text { for bulk analyses (e.g., } N=5 \text { ): } \sigma_{\text {total }}=\sqrt{180^{2}+\sigma_{\text {lab }}^{2}}
\end{aligned}
$$

Because of the variability of the age anomaly, corrected ${ }^{14} \mathrm{C}$ dates on Rabdotus shells can never be more precise than approximately $\pm 200 \mathrm{yr}$. The analytical error for Holocene fossil samples is generally much smaller than this (typically 20 to $80 \mathrm{yr}$ ) and thus does not contribute very much to the overall error. However, in older snail samples in which analytical errors are on the order of several hundred years, the variability of the age anomaly contributes relatively little to the overall error of the corrected ages.

It should be noted that these correction factors apply to samples taken from the last whorl of Rabdotus shells. Pieces of shell from the apical whorls of the shells are expected to have higher age anomalies, based on the observed pattern of ontogenetic variation. For analyses of whole shells, the age anomaly correction should be similar to or slightly higher than the correction for samples from the last whorl, since the last whorl comprises the bulk of the shell.

The variability of age anomalies for Rabdotus reported here $(\sigma=180 \mathrm{yr})$ is smaller than that reported earlier for land snails from the Negev Desert $(\sigma=230 \mathrm{yr}$ for Trochoidea and $500 \mathrm{yr}$ for Sphincterochila) and much smaller than that reported for Jamaican Pleurodonte $(\sigma=1200 \mathrm{yr})$ (Goodfriend 1987). Thus Rabdotus is a relatively good land snail taxon for dating. Its age anomalies are also smaller than those for most other snails (usually in the range of 1000 to $2500 \mathrm{yr}$; see references in first paragraph of Introduction). This relatively small average age anomaly of $+700 \mathrm{yr}$ implies that only a small proportion of the shell carbonate carbon of Rabdotus derives from ancient carbonate (limestone) sources (8\%, calculated according to Goodfriend 1987, Equation 2). Consequently, the standard correction for isotopic fractionation gives a good approximation to the actual fractionation correction. It is not necessary to use the more accurate but more complicated correction (Goodfriend 1987, Equation 8), which also takes into account the contribution of limestone to the $\delta^{13} \mathrm{C}$ value.

Materials that have been widely used for ${ }^{14} \mathrm{C}$ dating of Quaternary deposits and archeological sites in the southern Great Plains include charcoal, soil organics, bone, and occasionally wood. Although charcoal and wood remain the best materials for ${ }^{14} \mathrm{C}$ analysis, they are often not preserved at sites in 
the region. Corrected ${ }^{14} \mathrm{C}$ dates on Rabdotus shells will have poorer precision, with errors on the order of \pm 200 yr. However, they are still generally preferable to soil organic ${ }^{14} \mathrm{C}$ analyses for dating of strata, as soil organics are easily contaminated by subsequent root growth and generally accumulate over long periods of time (perhaps hundreds of years). Bone can be dated with better precision than land snail shells, as bone organics do not have age anomalies. However, the accuracy of bone dates depends on the degree of preservation of the bone organics (Stafford et al. 1990). If the available bone is not well preserved, then Rabdotus shells would be a preferable material for ${ }^{14} \mathrm{C}$ dating.

\section{ACKNOWLEDGMENTS}

Shell samples for this study were provided by M G Harasewych, R Hershler, and P Greenhall of the National Museum of Natural History. M Quigg and C Lintz of TRC-Mariah Associates made available to us their results of modern Rabdotus ${ }^{14} \mathrm{C}$ analyses.

This study was supported by NSF grant nr SBR9510869 to Goodfriend and Ellis.

\section{REFERENCES}

Abbott JT, Ellis GL, Goodfriend GA. 1995. Chronometric and integrity analysis using land snails. In: Abbott $\mathrm{JT}$, Trierweiler WN, editors. NRHP significance testing of 57 prehistoric archeological sites on Fort Hood, Texas. Volume 2. Archeological Resource Management Series, US Army, Fort Hood. Research report nr 34:801-14.

Abbott JT, Goodfriend GA, Ellis GL. 1996. Landsnail investigations. In: Trierweiler WN, editor. Archeological testing at Fort Hood: 1994-1995. Volume 2. Archeological Resource Management Series, US Army, Fort Hood. Research report nr 35:619-36.

Burleigh R, Kerney MP. 1982. Some chronological implications of a fossil molluscan assemblage from a Neolithic site at Brook, Kent, England. Journal of Archaeological Science 9:29-38.

Ellis GL, Goodfriend GA. 1994. Chronometric and siteformation studies using land snail shells: Preliminary results. In: Trierweiler WN, editor. Archeological investigations on 571 prehistoric sites at Fort Hood, Bell and Coryell Counties, Texas. Archeological Resource Management Series, US Army, Fort Hood. Research report nr 31: 183-201.

Ellis GL, Goodfriend GA, Abbott JT, Hare PE, von Endt DW. 1996. Assessment of integrity and geochronology of archeological sites using amino acid racemization in land snail shells: examples from central Texas. Geoarchaeology 11: 189-213.

Evin J, Marechal J, Pachiaudi C, Puissegur JJ. 1980. Conditions involved in dating terrestrial shells. Radiocarbon 22(2):545-55.

Fullington RW, Pratt WL. 1974. The aquatic and land Mollusca of Texas. Part 3. Dallas Museum of Natural History Bulletin 1. Dallas: Dallas Natural Science Association. iv $+48 \mathrm{p}$.

Goodfriend GA. 1987. Radiocarbon age anomalies in shell carbonate of land snails from semi-arid areas. Radiocarbon 29:159-67.

Goodfriend GA, Hood DG. 1983. Carbon isotope analy- sis of land snail shells: implications for carbon sources and radiocarbon dating. Radiocarbon 25: 810-30.

Goodfriend GA, Stipp JJ. 1983. Limestone and the problem of radiocarbon dating of land-snail shell carbonate. Geology 11:575-7.

Johnson L. Life and death as seen at the Bessie Kruze Site (41WM13) on the Blackland Prairie of Williamson County, Texas. Texas Dept of Transportation and Texas Historical Commission, Austin, Texas. Forthcoming.

Pilsbry HA. 1946. Land mollusca of North America (north of Mexico). Volume 2, Part 1. Monographs of the Academy of Natural Sciences of Philadelphia 3., Philadelphia: George W. Carpenter Fund. vii + 520 p.

Quigg JM, et al. 1996 Early archaic use of the Concho River terraces: cultural resource investigations at $41 T G 307$ and 41TG309 Tom Green County, San Angelo, Texas. Texas Department of Antiquities Technical Report no. 11058. Austin: TRC Mariah Associates.

Stafford TW. 1993. AMS ${ }^{14} \mathrm{C}$ dating in geoarchaeology: field and laboratory controls on absolute accuracy and precision. Abstracts with Programs, Geological Society of American 1993 Annual Meeting (Boston; October 1993): A187.

Stafford TW, Hare PE, Currie, L, Jull AJT, Donahue D. 1990. Accuracy of North American human skeleton ages. Quaternary Research 34:111-20.

Stuiver M, Becker B. 1993. High-precision decadal calibration of the radiocarbon time scale, AD 1950-6000 BC. Radiocarbon 35(1):35-65.

Toomey RS, Stafford TW. 1994 Paleoenvironmental and radiocarbon study of the deposits from Hall's Cave, Kerr County, Texas. Program and Abstracts, 65th Annual Meeting of the Texas Archeological Society (Lubbock, Texas; November 1994): 96.

US Environmental Data Service. 1969. Climatology of the United States. Nr 60-41. 